\title{
Adenomatoid tumor of the uterus; report of a rare incidentaloma
}

\author{
Reetu Kundu $^{1 *}$, Harsh Mohan ${ }^{1}$, Alka Sehgal ${ }^{2}$, Navneet Takkar ${ }^{2}$ \\ ${ }^{1}$ Department of Pathology, Government Medical College and Hospital, Chandigarh-160030, Punjab, India \\ ${ }^{2}$ Department of Obstetrics \& Gynecology, Government Medical College and Hospital, Chandigarh-160030, Punjab, \\ India
}

Received: 3 June 2014

Accepted: 1 July 2014

\author{
*Correspondence: \\ Dr. Reetu Kundu, \\ E-mail: reetukundu@gmail.com
}

(C) 2014 Kundu R et al. This is an open-access article distributed under the terms of the Creative Commons Attribution Non-Commercial License, which permits unrestricted non-commercial use, distribution, and reproduction in any medium, provided the original work is properly cited.

\begin{abstract}
Adenomatoid tumor of the uterus is extremely rare and usually an incidental finding in the uteri removed surgically for some other cause as in the present case. The histogenesis of this tumor has been controversial ever since its discovery, although the most favored and proposed is a mesothelial origin. Grossly it is usually mistaken for a leiomyoma. The tumor may have a variety of histomorphologic patterns with rare bizarre appearances, at times leading to an erroneous diagnosis of metastatic adenocarcinoma.
\end{abstract}

Keywords: Adenomatoid tumor, Uterus, Mesothelial

\section{INTRODUCTION}

Adenomatoid tumors are benign tumors of mesothelial origin, seen preferentially in the male and female reproductive system. ${ }^{1}$

The gonadal locations include epididymis, spermatic cord, tunica albuginea, prostate, and ejaculatory duct in males and the fallopian tube, uterus and hilum of the ovary in females. Rarely can they be seen at the extragonadal sites.

They are relatively unusual neoplasms in the uterus where they are often detected incidentally in hysterectomy specimens removed for an unrelated cause. $^{2,3}$ These are often grossly mistaken for leiomyomas which are frequent in occurrence. ${ }^{4}$ In some instances, these can have bizarre histomorphological appearances and hence need to be distinguished from malignant tumors. ${ }^{2}$

\section{CASE REPORT}

A 47-year-old multiparous perimenopausal female presented to the gynecologist with symptoms of uterine prolapse. On gynecologic examination she was found to have prolapse and was posted for an elective surgery.

Total hysterectomy specimen measured 10.5 x 7 x $5.2 \mathrm{~cm}$ and weighted $55 \mathrm{gm}$. Externally, a single subserosal nodule near the cornua measuring $2 \mathrm{~cm}$ in diameter was identified (Figure 1a).

The cervical lips were hypertrophied. On cut section, endometrial and myometrial thickness was $0.3 \mathrm{~cm}$ and $2.2 \mathrm{~cm}$ respectively. Cut section of the nodule was solid grey white and firm.

Hematoxylin and Eosin $(H \& E)$ stained sections from the subserosal nodule showed an unencapsulated tumor composed of cystic spaces and tubular configurations lined by indistinct to flattened to cuboidal mesothelial cells (Figure 1b, 1c).

There was no pleomorphism, nuclear hyperchromasia, mitosis or necrosis. No infiltration into the surrounding myometrium was seen. Rest of the specimen showed endometrium in proliferative phase, adenomyosis uteri and chronic cervicitis with surface keratinisation of ectocervix. 

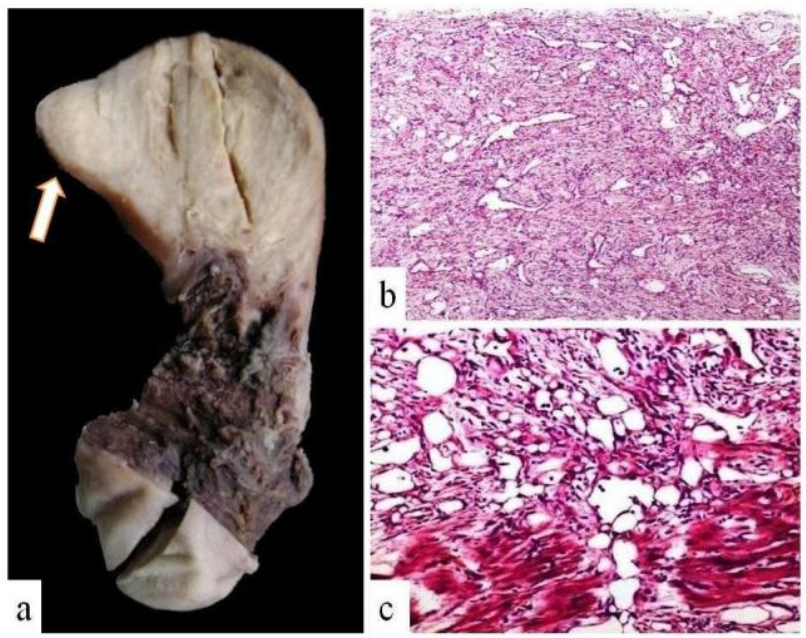

Figure 1: Uterine adenomatoid tumor: (a) Gross photograph showing subserosal nodule located near right cornua (arrow). (b) Photomicrograph showing the tumor composed of cystic and tubular spaces (H\&E, x200). (c) Higher magnification depicting an admixture of tubular pattern with cystic spaces lined by bland mesothelial cells and an ill-defined lower border with the surrounding myometrium $(\mathrm{H} \& \mathrm{E}$, $\mathrm{x}$ 400).

\section{DISCUSSION}

Adenomatoid tumor was first described in 1945 by Golden and $\mathrm{Ash}^{5}$ as a small firm asymptomatic intrascrotal mass, occurring in third to fifth decades of life. The histogenesis of this tumor has been controversial; the proposed possibilities are endothelial, Müllerian, mesothelial and mesonephric origins, although the most favored one is a mesothelial origin based on the ultrastructural and immunohistochemical studies. ${ }^{2,4,6}$

In the female genital tract, these tumors are commonly encountered in fallopian tube. ${ }^{7}$ Rarely do they occur in the uterus as in our case. These are asymptomatic and found incidentally in uteri removed for other causes. ${ }^{2}$ Our patient underwent total hysterectomy for prolapse and the tumor detection was an incidental one. A subserosal location near the cornua found in our case is usually the classical site. ${ }^{2}$ The tumor measured $2 \mathrm{~cm}$ in diameter. The cut section showed a grey white tumor with a firm consistency. Whorling was not as pronounced as in a leiomyoma. These tumors usually mimic a fibroleiomyoma on gross. ${ }^{4}$ The ill-defined margins with the surrounding myometrium help distinguish them from leiomyomas on gross, which are discretely welldelineated. $^{2}$

Histological appearances are varied with adenoid, angiomatoid, cystic, glandular, solid and tubular patterns. Rare morphologic patterns include oncocytic and reactive ischemia. ${ }^{6}$ Our case showed an admixture of tubular pattern with cystic spaces lined by bland mesothelial cells. A tubular pattern when seen in isolation may mimic metastatic adenocarcinoma. ${ }^{2,6}$ However, an admixture of patterns, bland cell morphology with insignificant mitoses help in making a distinction. ${ }^{6}$

These tumors are purely benign with no recurrences/metastasis and need to be distinguished from other tumors at times which include leiomyomas, angiomas, lymphangiomas, angiomyomas and metastatic adenocarcinomas. ${ }^{2,4,6,8,9}$ The distinction can be made on the basis of gross findings and careful evaluation of microscopic appearances. At times identification of adenomatoid tubules is difficult and these may be overlooked as empty spaces within the myometrium. These are the few instances where immunohistochemistry can be a useful adjunct. Majority of these tumors are immunoreactive for cytokeratins, calretinin, HMBE-1 and vimentin. ${ }^{2,4}$

To conclude, this case report gives an insight into the histomorphological findings of this tumor which is exceedingly rare and often overlooked because of its low incidence, lack of awareness and common differentials. The key to an accurate diagnosis is careful observation of findings on routine light microscopy supported by special stains and sometimes immunohistochemical stains.

Funding: No funding sources Conflict of interest: None declared Ethical approval: Not required

\section{REFERENCES}

1. Sakurai N, Yamamoto Y, Asakawa Y, Taoka H, Takahashi K, Kubushiro K. Laparoscopically resected uterine adenomatoid tumor with coexisting endometriosis: case report. J Minim Invasive Gynecol. 2011;18(2):257-61.

2. Nogales FF, Isaac MA, Hardisson D, Bosincu L, Palacios J, Ordi J et al. Adenomatoid tumors of the uterus: an analysis of 60 cases. Int J Gynecol Pathol. 2002;21(1):34-40.

3. Nakayama $\mathrm{H}$, Teramoto $\mathrm{H}$, Teramoto $\mathrm{M}$. True incidence of uterine adenomatoid tumors. Biomed Rep. 2013;1(3):352-4.

4. Huang CC, Chang DY, Chen CK, Chou YY, Huang SC. Adenomatoid tumor of the female genital tract. Int J Gynecol Obstet. 1995;50(3):275-80.

5. Golden A, Ash JE. Adenomatoid tumors of the genital tract. Am J Pathol. 1945;21:63-79.

6. Sangoi AR, McKenney JK, Schwartz EJ, Rouse RV, Longacre TA. Adenomatoid tumors of the female and male genital tracts: a clinicopathological and immunohistochemical study of 44 cases. Mod Pathol. 2009;22(9):1228-35.

7. Srigley JR, Colgan TJ. Multifocal and diffuse adenomatoid tumor involving uterus and fallopian tube. Ultrastruct Pathol. 1988;12:351-5.

8. Iwasaki I, Yu TJ, Tamaru J, Asanuma K. A cystic adenomatoid tumor of the uterus simulating 
lymphangioma grossly. Acta Pathol Jpn. 1985;35:989-93.

9. Otis CN, Carcangiu ML, Gaffey MJ, Mills SE. Uterine adenomatoid tumors (Mesomyomas). A distinct morphologic subtype of adenomatoid tumor to be distinguished from metastatic adenocarcinoma. Lab Invest. 1994;70:A93.

DOI: $10.5455 / 2320-1770 . i j \operatorname{cog} 20140916$

Cite this article as: Kundu R, Mohan H, Sehgal A, Takkar N. Adenomatoid tumor of the uterus; report of a rare incidentaloma. Int J Reprod Contracept Obstet Gynecol 2014;3:769-71. 